\title{
The surgical treatment of acute spinal paralysed patients
}

\author{
U Bötel, E Gläser and A Niedeggen
}

Department of Neurotraumatology and Spinal Cord Injuries, BG Kliniken 'Bergmannsheil', University Hospital, Bochum, Germany

\begin{abstract}
Following the basic principles of Sir Ludwig Guttmann in respect of the comprehensive care and management of spinal cord injured patients, the German SCI centers try to admit those freshly injured preferably on the first day of onset, providing spinal surgery and intensive care. In our series of recent comprehensive spinal paralysed patients admitted from Jan 1st 1993 to Dec 31st 1995178 patients requested operative decompression and stabilization out of a total of 255 patients. $51.4 \%$ of the patients had been operated within the first $24 \mathrm{~h}$, but $10.5 \%$ later than 2 weeks. A high incidence of reoperations $(45.2 \%)$ must be noted in cases operated prior to the admittance to the SCI center due to failures of instrumentation or lack of anterior reconstruction. Nineteen patients with various spinal tumors underwent surgical treatment, and seven patients with spondylitis and severe neurological deficit. Only $64.4 \%$ of the 1 st day admissions came in time for administration of high dose methylprednisolone according to the NASCIS II study. The additional pelvic and long bone fractures were operated on following the principles of the Swiss AO, thus achieving immediate mobilization as was also possible after surgical spine stabilization. Neurological recovery could only be found in those with incomplete lesions in more than $50 \%$ but also two with neurological deterioration had to be accepted in the paraplegic cohort. ${ }^{8}$ Eight who were tetraplegic and 14 with paraplegia died within the first 3 months, but nine with paraplegia had a tumor or spondylitis.
\end{abstract}

Keywords: epidemiology of SCI; surgical stabilization of the spine; traumatological operations in SCI patients; neurological recovery; ultrahigh methylprednisolone administration

\section{Introduction}

Since Sir Ludwig Guttmann developed his fundamental ideas of comprehensive care and management of spinal cord injury $(\mathrm{SCI})^{1}$ following the years after 1944 , numerous SCI centers have been founded all over the world. In Germany the first centers in Bayreuth, Bochum and Koblenz had not been set up earlier than 1952 starting the treatment in his sense as soon as SCI had been diagnosed and not waiting for the healing of vertebral fractures. According to the experiences of that time the treatment was conservative $^{2}$ having also in mind, that L Guttmann could not see any advantages in surgical treatment. ${ }^{1}$

The history of spinal surgery only reaches back to the end of the 19th century, when Hadra developed a posterior wiring technique for unstable dislocations. ${ }^{3}$ Albee tried to achieve stability and fusion by the use of cortical bone grafts but without success. ${ }^{4}$ Also the introduction of paraspinous plates by Holdsworth and Hardy $^{5}$ and others did not solve the problem and was one of the main reasons for the objections of Guttmann to the surgical treatment of SCI. ${ }^{1}$ Some better results could be gained by using Harrington

Correspondence: U Bötel rods, ${ }^{6}$ but the use of transpedicular screws and plates by Roy-Camille was really revolutionary ${ }^{7}$ and opened the gateway to the modern fixation principles, since also the principles of a dynamic spring instrumentation by Weiss ${ }^{8}$ could not be convincing despite some improvements by additional devices.9 Magerl developed an external spinal fixator, ${ }^{10}$ which led to the construction of internal fixators based on the ideas of Kluger and Dick ${ }^{11,12}$ and other short-range instrumentation with stable angulation. ${ }^{13}$ In respect of careful and safe decompression of the spinal cord it was not only posterior approaches that had been successful. Anterior decompression and stabilization was preferred by Riska and Kostuik, among many others. ${ }^{14,15}$

For a satisfactory final result not only stable primary instrumentation is essential but also safe fracture healing in anatomical alignment. For that autologous bone grafting is necessary as was already introduced for the cervical spine by Robinson and Cloward. ${ }^{16,17}$ The surgical procedure for fractures and dislocations of the cervical spine has been standardized with grafting combined with an instrumentation. ${ }^{18,19}$

Despite successful restoration of the spine and also the spinal canal only little can be done in respect of 
the spinal cord, as many authors pointed out. ${ }^{9,20}$ The predominant goal of spine surgery is the restoration of stability and good alignment-not the spinal cord. Some new aspects in the treatment of the acute SCI arose by the NASCIS II study, published by Bracken et al, provided that neurons had not been previously destroyed by the trauma. ${ }^{21}$ Since the publication many SCI patients in Germany have been treated according to the prescriptions depending on the time of admission. Other potential drugs are still under investigation. ${ }^{22}$ Basic research in neural regeneration might solve some of the problems of SCI patients in the future. ${ }^{23}$

\section{Materials}

In Germany the philosophy of Guttmann's comprehensive care and management has been followed since 1952 , although the treatment of the injured spine has changed markedly since his time, ${ }^{24-26}$ but the essential points of his approach to comprehensive cover beginning the day of onset of paraplegia are still valuable and have to be followed.

For illustration and verification of the German point of view, which is different to the American, Dutch, or Austrian, we reviewed the case-histories of all patients admitted with recent tetraplegia or paraplegia to the department of neurotraumatology, and spinal cord injuries of the 'Bergmannsheil' Hospital Bochum, University Hospital, from Jan 1st 1993 to Dec 31st 1995. A total of 255 patients had to be treated, 205 $(80.4 \%)$ suffered from posttraumatic tetraplegia or paraplegia, $50(19.6 \%)$ had non-traumatic conditions. The mean age was 39.3 years $(2-82$ years $)$ meaning a steady increase, since the mean age only 15 years ago ranged at 24 years. The distribution of gender was the same as in the over-all German statistics: $27 \%$ female, $72 \%$ male and $1 \%$ children. Eighty patients were tetraplegic $(31.4 \%)$ including seven permanent ventilator-dependent persons meaning $8.75 \%$ of all with tetraplegia. One hundred and seventy-five patients were paraplegic $(68.6 \%)$.

The majority of posttraumatic SCI arose from road accidents slightly predominant by motorcycles $(45.9 \%)$, whilst work injuries only originated $16.1 \%$ of the cases, mainly by falls from a height. Falls were also the reason for paraplegia in cases with suicide attempts but violence played an unimportant role in contrast to other countries. Falls from trees, staircases, or windows were other causes (Table 1).

The basic demand of beginning the comprehensive care in the specialized center on the first day of injury could not be fulfilled, although the center is part of a hospital for maximum treatment. This is partly due to lack of beds in the intensive care unit or the center itself, partly due to the fact that spine surgery is meanwhile carried out in various hospitals, although often a lack of sufficient experience has to be noted. This meant that only $42.2 \%$ of acutely injured patients reached the SCI center within the first $24 \mathrm{~h}$, and only
$64.4 \%$ of these had the benefit of methylprednisolone administration in the first $8 \mathrm{~h}$ window, some by inquiry by the first non-specialized hospital to the SCI center. $25 \%$ were admitted 2 weeks and more after the injury, many of them with complications including pressure sores, contractures, and respiratory deficiencies (Table 2). The additional injuries and important diseases not related directly to the spinal trauma will be discussed later in the respective section.

Among the non-traumatic admissions requiring surgical treatment six patients had primary tumors of the spine, 13 metastatic spinal tumors and seven had spondylitis (Table 3 ).

Table 1 Admission of recent cases of paraplegia Jan 1st 1993-Dec 31st 1995

\begin{tabular}{llrl}
\hline Traumatic & road acc. & 94 & $(45.9 \%)$ \\
& work & 33 & $(16.1 \%)$ \\
& sport and diving & 10 & $(4.9 \%)$ \\
& suicide & 13 & $(6.3 \%)$ \\
& violence & 2 & $(0.9 \%)$ \\
& others & 53 & $(20.9 \%)$ \\
Non-traumatic & 205 & $(80.4 \%)$ \\
& 50 & $(19.6 \%)$ \\
Tetraplegia & total & 255 & \\
& 80 & $(31.4 \%)$ \\
& & $(7$ permanent \\
& & & ventilator \\
& & & dependent) \\
Paraplegia & & & $(8.75 \%)$ \\
\end{tabular}

Table 2 Admission after trauma $(n=205)$

\begin{tabular}{lll}
\hline $24 \mathrm{~h}$ & 87 & $(42.2 \%)$ \\
$2-7$ days & 38 & $(18.7 \%)$ \\
$7-14$ days & 27 & $(13.3 \%)$ \\
$>14$ days & 53 & $(25.8 \%)$ \\
\hline
\end{tabular}

MP-adminstration (NASCIS II); $56 \quad(64.4 \%$ of 1 st day admissions)

Table 3 Tumors and Spondylitis with neurological deficit requiring operation

Primary

Plasmocytoma 3 non-Hodgkin-Lymphoma eosinophilic granuloma chordoma

Metastatic

bronchial cancer kidney and bladder cancer cancer of intestine prostatic cancer mamma cancer uterus cancer thyroid cancer

\section{Metastatic}

thyroid cancer

Spondylitis 


\section{Immediate management}

In all patients admitted in the first $8 \mathrm{~h}$ after injury high dose methylprednisolone was administered according to the prescriptions of the NASCIS II study. ${ }^{21}$ Our investigations on the pharmacodynamics and pharmacokinetics of methylprednisolone (MP) showed that protein bound MP did not enter the cerebral spinal fluid (CSF). The plasma concentration of MP exceeded $1^{-5} \mathrm{Mol} / \mathrm{l}$. The ratio of plasma: CSF levels was $0.1-$ 0.25 which meant that only a very small amount of unbound MP was available for the repair of cell membranes in the spinal cord. ${ }^{27}$

The benefit of methylprednisolone administration may be demonstrated in the report of a previous series of 172 patients with paraplegia compared with a group of 28 paraplegic patients who had the administration of methylprednisolone (MP) according to the NASCIS II scheme and who underwent the same types of operation. In the group with operations without MP, $78 \%$ remained in the same Frankel grade, $15 \%$ had an improvement and 5\% recovered: whereas in the group with MP only 50\% remained in the previous Frankel grade, $16 \%$ had an improvement and $14 \%$ recovered but these figures can only suggest a tendency to benefit.

The fractures of the spine leading to tetraplegia or paraplegia and requiring surgical stabilization have been classified according to the system of Magerl, Harms, Gertzbein, Aebi and Nazarian. ${ }^{28}$ Peaks of involvement could be noted at the C5 and C6 level in the cervical spine, the T5-T7 level for the thoracic spine, and in the thoraco-lumbar junction T12-L2, as most other investigators also have found (Figure 1). In the classification system A stands for compressive and burst fractures only involving the anterior vertebral column by axial and/or flexive load, B for distraction injuries caused by hyperflexion or hyperextension, and



Figure 1 Distribution of unstable vertebral fractures leading to surgical stabilization and classification

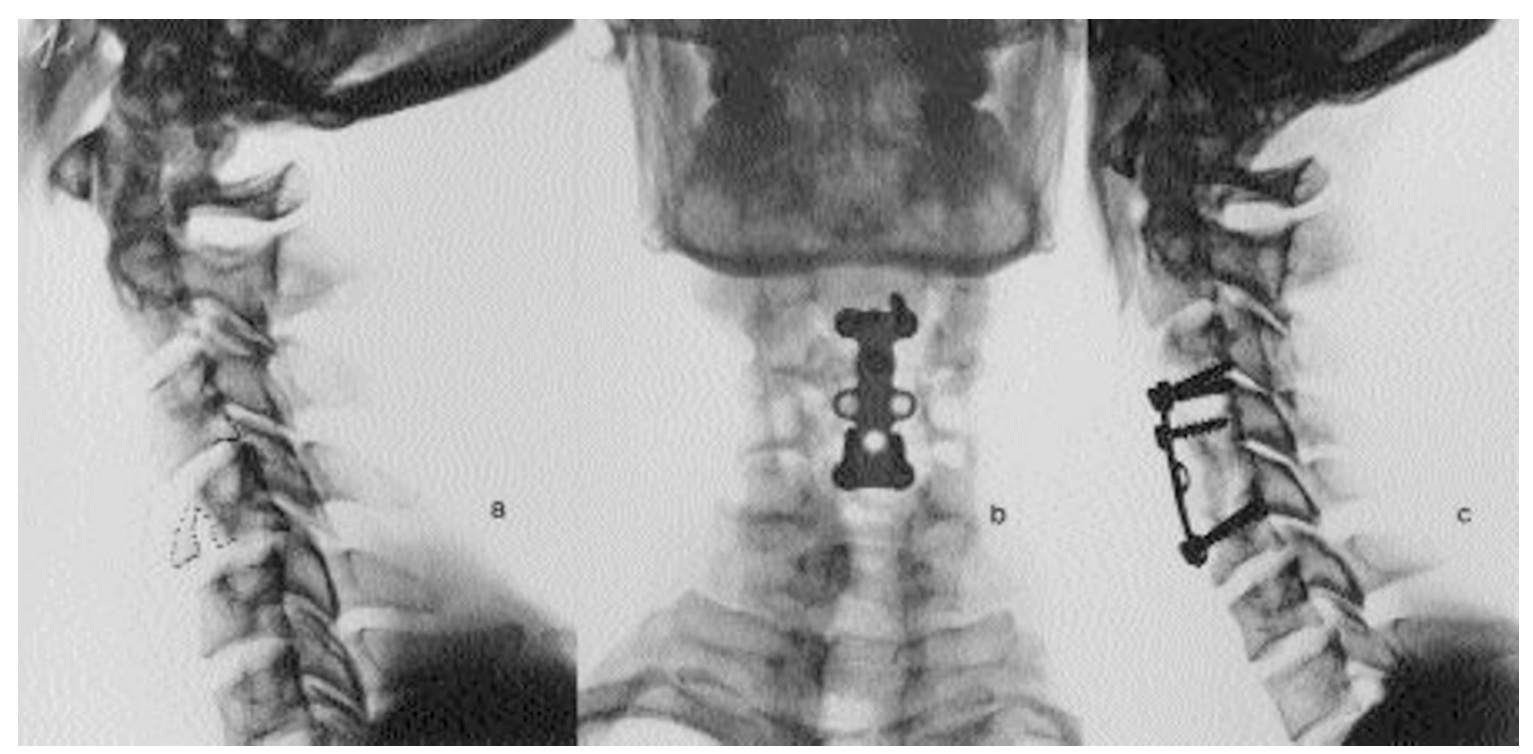

Figure 2 Male, 23 years. (a) burst fracture of C4 with complete tetraplegia below C5. (b,c) corporectomy of C4, interbody fusion with iliac crest and double-H-plate. Perfect alignment and stable healing 
$\mathrm{C}$ for unstable injuries in combination with rotational forces. B and $\mathrm{C}$ types are highly unstable and are often followed by spinal cord damage, whereas in the $\mathrm{A}$ types only the burst fractures threaten the spinal cord. We have noted in our cases, that in C5 fractures with tetraplegia, mainly burstfractures of type A could be found contrary to $\mathrm{C} 6$ and $\mathrm{C} 7$ injuries with predominant dislocations of the $\mathrm{B}$ type. In midthoracic injuries $\mathrm{T} 5-\mathrm{T} 7$ rotational injuries prevailed, but in the thoraco-lumbar junction $\mathrm{T} 12$ fractures $\mathrm{B}$ and $\mathrm{C}$ types were predominant, whereas in $\mathrm{L} 1$ and $\mathrm{L} 2$ burst fractures of the A type showed the same numbers as rotational injuries from the $\mathrm{C}$ type (Figure 1).

The principles for surgical stabilization followed the experiences of the last 20 years pointing out some fundamental demands on the surgical procedure:

- short instrumentation with secured angulation

- fusion only of the destroyed segments

- use of autologous bone graft

- abandonment of external bracing

- immediate mobilization.

In the cervical spine treatment is standardized, ${ }^{18,19}$ predominantly anterior interbody fusions with tricortical autologous bonegrafts of the iliac crest in combination with plates were used; burst fractures required corporectomies (Figure 2). In cases of necessary additional decompression posteriorly combined stabilizations were necessary; an exclusive posterior approach was mainly carried out in cases with interlocking facets.

For the stabilization of thoracic and lumbar fractures and dislocations the posterior approach was preferred with decompression of the spinal canal, reconstruction of the anterior column and instrumentation with plates in combination with a transpedicular USI-system $^{13}$ (Figure 3) or internal fixators. ${ }^{12,29}$ Only in three cases a primary combined posterior/anterior approach had to be done (Table 4).

According to experiences in recent years with increasing numbers of spinal operations outside the SCI centers, 42 patients $(23.6 \%)$ were admitted who had already been operated on but $19(45.2 \%)$ of these

Table 4 Primary spinal operative stabilization (178 out of $205(86.8 \%))$

\begin{tabular}{llc}
\hline Cervical & $\begin{array}{l}\text { dens and C1/2 } \\
\text { anterior instrumented } \\
\text { cervical fusion }\end{array}$ & 4 \\
& $\begin{array}{l}\text { posterior instrumented } \\
\text { cervical fusion }\end{array}$ & 6 \\
& $\begin{array}{l}\text { combined instrumented } \\
\text { cervical fusion }\end{array}$ & 7 \\
& dorsal stabilization & 65 \\
Thoraic and & 109 \\
lumbar & laminectomy & 3 \\
& primary operation in & 1 \\
& $\begin{array}{l}\text { other hospital } \\
\text { necessary corrective }\end{array}$ & $42(23.6 \%)$ \\
& re-operation in these & $19(45.2 \%)$ \\
& corrective re-operation & $9(5.6 \%)$ \\
\hline
\end{tabular}

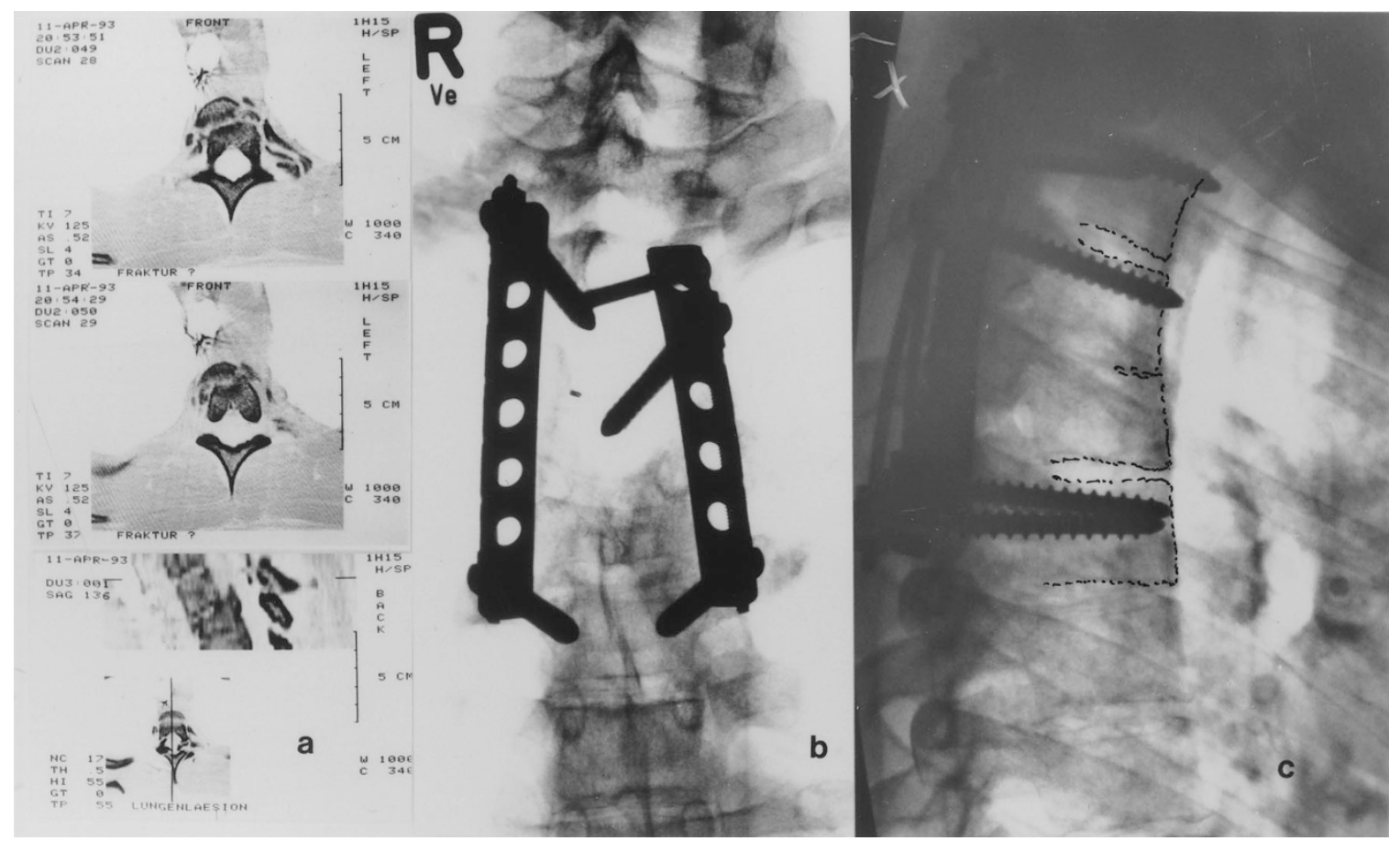

Figure 3 Male, 21 years. (a) rotational flexion-distraction fracture of T4 (type C). (b,c) open reduction and decompression, interbody fusion T3/4, plating in combination with USI-system. Good alignment and stable healing 
had to undergo corrective re-operations in our center, whilst only nine $(5.6 \%)$ of our own patients had to have further operations.

Ninety-two patients $(51.4 \%)$ inclusive of having operations in other hospitals could be stabilized on the day of injury, $54(30.5 \%)$ in the first week, 13 patients $(7.6 \%)$ in the second week and $19(10.5 \%)$ later than 2 weeks. The time of operation depended on the day of admission on the one hand but on the state of the patient at the other, especially regarding patients with severe polytrauma and thoracic injuries.

Nineteen patients with tumors causing paraplegia had to be operated on, 14 by tumor resection and instrumentation, five only by palliative instrumented stabilization. Seven cases with spondylitis underwent corporectomy and a combined instrumented stabilization following the same principles as in the trauma cases (Table 5).

\section{Additional injuries and diseases}

In trauma patients we found 132 important additional injuries, especially severe chest traumas which required extensive therapy in the intensive care unit. We also found severe brain traumas of grade II and III in 16 cases, seven abdominal injuries and a number of additional fractures (Table 6).

Table 5 Operations for tumors and for spondylitis

\begin{tabular}{lr}
\hline Tumor resection and instrumented & 14 \\
stabilization & \\
Palliative dorsal stabilization & 5 \\
Corporectomy and combined & 7 \\
instrumented stabilization & 26 \\
\hline
\end{tabular}

Table 6 Additional injuries

Severe thoracic trauma

(hemo- and pneumothorax, serial

rib-fractures, lung contusion)

Severe brain trauma grade II + III

Maxillary fractures

Fractures of shoulder girdle

Fractures of upper arm

Fractures of fore arm

Hand fractures

Pelvic fractures

Femoral fractures

Knee disruptions

Fractures of lower leg

Fractures of ankle and foot

Diaphragmatic disruption

Abdominal injuries

(spleen, liver, intestine, bladder)
Also important diseases pre-existing the paraplegia require to be mentioned, as they complicate the course of treatment markedly, especially cardiac and respiratory deficiencies, psychosis, and alcoholism (Table 7).

Besides the spine operations 96 other surgical procedures had to be done, some because of their life threatening kind, others in respect of necessary

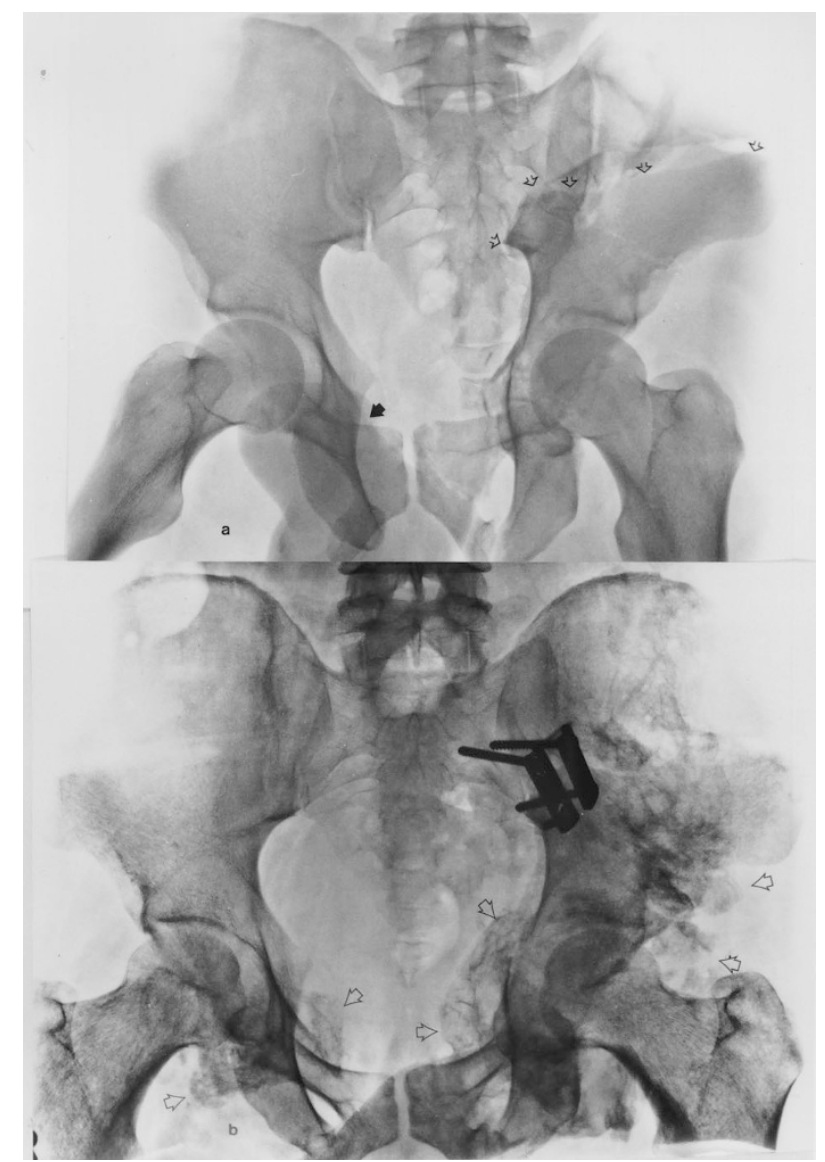

Figure 4 Male, 21 years, same patient as in Figure 3. (a) unstable pelvic fracture of the anterior and posterior ring and left iliac bone. (b) 6 weeks after reconstruction and posterior plating with early mobilization. Note heterotopic ossification

Table 7 Important additional diseases

Cardiac deficiency (CHD, cardiac

insufficiency, cardiac operations)

$\begin{array}{ll}\text { Psychosis } & 14\end{array}$

Alcoholism $\quad 12$

Osteoporosis 13

Bekhterew's disease 4

Scoliosis

Poliomyelitis

Dysmelia

Additional tumors

Down's syndrome

Arterial obstruction 
Table 8 Necessary operations in connection with additional trauma or disease or extraspinal complications

\begin{tabular}{lr}
\hline Craniotomies & 8 \\
Thoracotomies & 4 \\
Laparotomies & 10 \\
Maxillary surgery & 2 \\
Tracheotomies & 18 \\
External fixator & 11 \\
Osteosynthesis by plating & 8 \\
Unreamed locking-nails & 7 \\
Pelvic osteosynthesis & 4 \\
Calcanea osteosynthesis & 3 \\
Joint reconstruction & 2 \\
Aortic endoprothesis & 2 \\
Thyroidectomy & 1 \\
Resection of neurinoma & 1 \\
Flap surgery & 9 \\
Myo-tenotomies & 2 \\
Baclofen-pump & 4 \\
& total \\
\hline
\end{tabular}

early mobilization. The stabilization of fractures followed the principles of the Swiss $\mathrm{AO}^{29}$ (Figure 4). But also bed sores, most of them arising from complications already existing at the time of admittance, had to be covered by mainly musculo-cutaneous flaps and six interventions were due to extreme untreatable spasticity (Table 8).

\section{Results}

The treatment of SCI involves in our department comprehensive care beginning with all necessary therapies, including surgical procedures, on the day of completing the course with discharge to the former or an adapted home, ready to take up the former profession or vocational training if possible regarding the age and potential of the patient. There were only a few cases where nursing homes were necessary. Also in ventilator dependent patients the post-hospital care could be provided in adapted flats or houses.

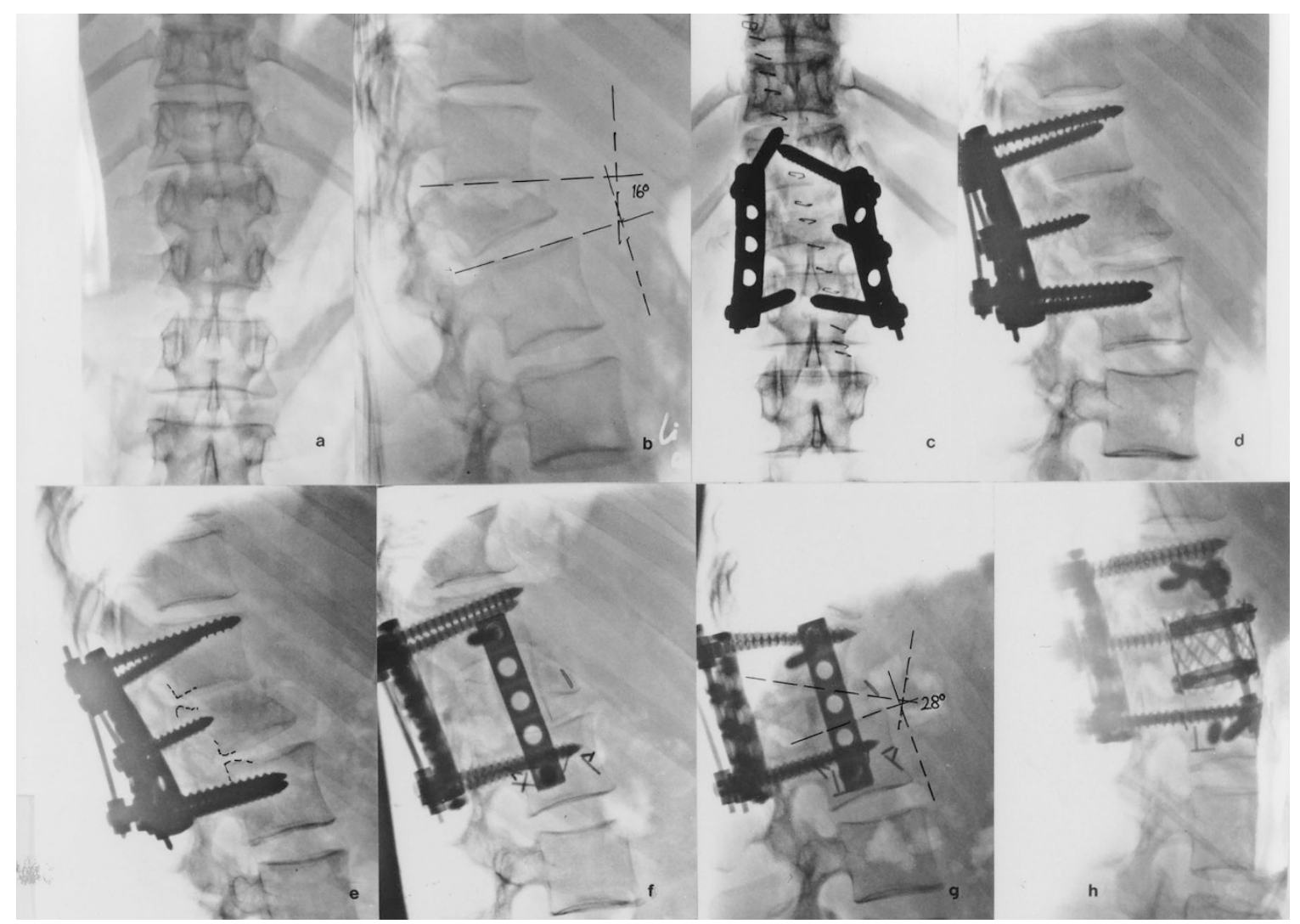

Figure 5 Female, 35 years. (a,b) complete burst fracture L1 (type A) with incomplete paraplegia Frankel C. (c,d) Operative reconstruction on the day of injury with intra- and intercorporal grafting and stabilization by plates and USI-system. Malposition of the upper left pediclescrew. (e) Although redislocation has to be noted recovery to Frankel D. (f) Re-operation by combined approach with good alignment and intercorporal fusion with iliac crest. Recovery to Frankel E. (g) Total breakdown by graft necrosis 3 months later. No further neurological deficit. (h) Second combined reconstruction with Harms titanium spacer. No neurological deficit 
A number of complications had also to be registered in connection with the spine surgery. We found a loss of correction of the spinal deformity in 28 cases but not all needing further corrective surgery. The majority of losses of correction derived from insufficient reconstruction of the anterior column especially in other hospitals, but also in our own hands we had to experience failures. In one case the deterioration started with a misplacement of a pedicle screw, leading to a combined reconstruction with anterior and posterior instrumentation and autologous corticocancellaneous interbody grafting with a good primary result but total breakdown after necrosis of the graft without any known reason, making necessary a second reconstructive surgery with use of a titanium spacer ${ }^{30}$ (Figure 5). Additionally wound hematomas and infections had to be stated as well as two cases of liquorrhea from the latter only one requiring revision.

The occurrence of transitional psychosis and one case of hepatitis $\mathrm{B}$, severe pneumonia with necessary

Table 9 Complications

\begin{tabular}{lr}
\hline Severe pneumonia & 21 \\
Lung abscess and pleural empyema & 2 \\
Wound infection & 8 \\
Bone infection & 3 \\
Liquorrhea & 2 \\
Loss of correction $\left(>5^{\circ}\right.$ ) & 28 \\
Failure of pedicle-screws (necessary correction) & 6 \\
Postoperative hematoma (revision) & 9 \\
Aortic disruption & 2 \\
Neurological deterioration & 2 \\
Transitional psychosis & 14 \\
Cerebral hypoxemia & 1 \\
Deep vein thrombosis & 18 \\
Embolism & 5 \\
Bed sores & 12 \\
Para-osteo-arthropathy (POA) & 9 \\
Extreme spasticity & 7 \\
lleus & 3 \\
Bladder stone & 1 \\
Hepatitis B & 1 \\
\hline
\end{tabular}

Table 10 Causes of death (out of 255)

\begin{tabular}{|c|c|c|}
\hline Tetraplegia & 8 & $\begin{array}{l}\text { (10\% of tetraplegic patients } \\
\text { all posttraumatic) }\end{array}$ \\
\hline Paraplegia & 14 & ( $8 \%$ of paraplegic patients) \\
\hline posttraumatic & 5 & $(2.9 \%)$ \\
\hline non-traumatic & 9 & $\begin{array}{l}(5.1 \%) \\
(18 \% \text { of non-traumatic) }\end{array}$ \\
\hline Pulmonary deficiency & & 5 \\
\hline Cardiac deficiency & & 3 \\
\hline Hypovolemia in polytrauma & & 2 \\
\hline Aortic disruption & & 2 \\
\hline Sepsis & & 3 \\
\hline Tumor disease & & 4 \\
\hline Embolism & & 3 \\
\hline & & total $22(8.6 \%)$ \\
\hline
\end{tabular}

intermittent intensive care and deep vein thrombosis with clinical signs influenced the duration of hospitalization, but also the long stay of ventilator-dependent patients before the post-hospital care could be organized (Table 9).

From the 255 admissions 22 patients died (8.6\%). Eight patients with tetraplegia died, all posttraumatic, meaning $10 \%$ of all tetraplegics. In those with paraplegia there were 14 deaths $(8 \%)$ but the distribution was quite different, as five were posttraumatic $(2.9 \%)$ and nine non-traumatic, meaning $18 \%$ of these also being of a higher age and in an advanced stage of their tumour disease. Causes of death were mainly pulmonary and cardiac deficiencies but also sepsis in the spondylitis cases and three from embolism (Table 10).

Excluding the deaths, the mean duration of hospitalization was 5.3 months, ranging from 2 weeks to 36 months. Short stays were seen in cases with spinal cord contusion, but the extremely long time of hospitalization was with ventilator-dependent patients and those with additional severe brain damage.

Looking at the neurological outcome we have to state, that all lesions classified as Frankel A remained in $\mathrm{A}$, but in the paraplegic cohort we had one deterioration from $\mathrm{D}$ to $\mathrm{A}$ and another from $\mathrm{C}$ to

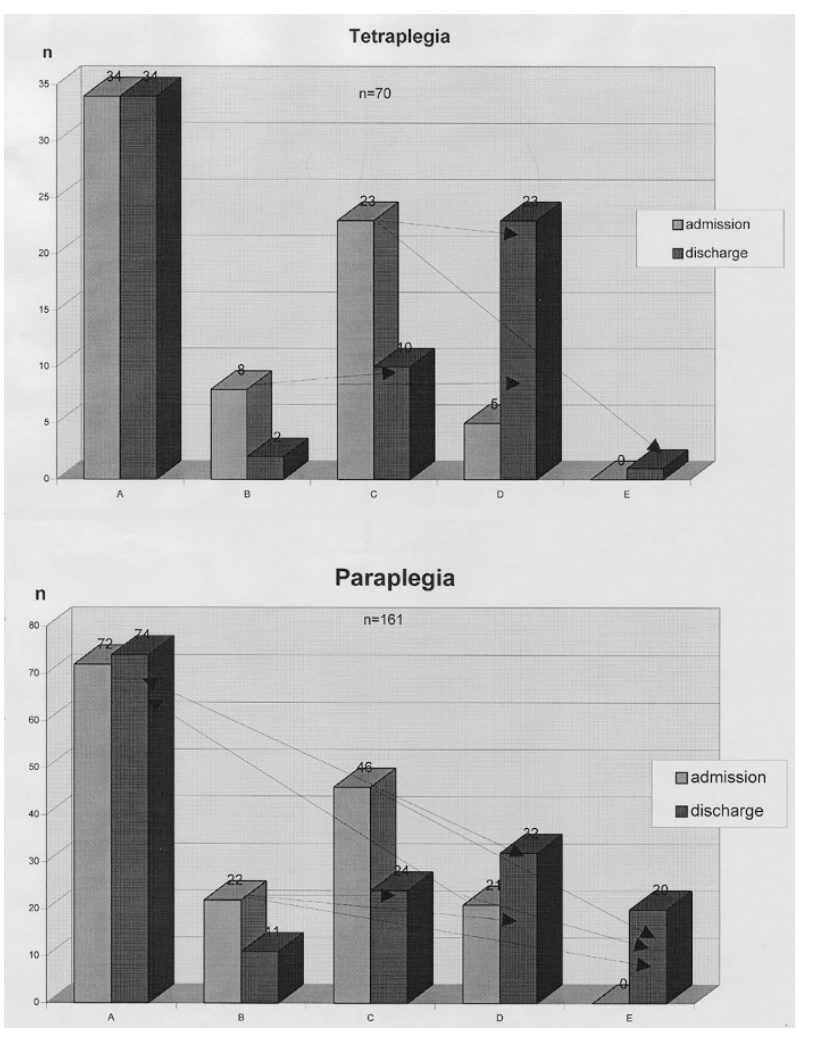

Figure 6 Recovery according to Frankel grades from admission to discharge 
A. In both groups all incomplete lesions B to D there were improvements in more than $50 \%$ of the previous lesion classification. Surprisingly only one tetraplegic patient improved to $\mathrm{E}$, but 20 patients in the paraplegic group did so (Figure 6).

\section{Conclusions}

Relying on the epidemiology and results we can state that the pretention of comprehensive care and management in a specialized SCI center from the first day of injury is not totally attainable in our country, although slightly more than $80 \%$ of the patients reached our center within the first week after injury. Looking at the large number of polytrauma patients with severe additional lesions, as well as concomittant other diseases clarifies that only those centers that are affiliated to big hospitals with maximal resources for treatment are eligible for the immediate care and management of all patients suffering from SCI. Intensive care units and specialized services are necessary for the management of life-threatening complications. Although desirable the admission to a SCI center must be postponed in all other cases, so that the SCI patient has to stay in a non-specialized hospital with the needed potentials as long as necessary to prevent complicating dangers for the patient, but it would be extremely desirable that the non-specialized hospital should contact the SCI center at the moment of detection of a spinal cord injury.

Spine surgery in the cervical region is standardized, producing very good results in respect of stability and alignment. Also surgery for the thoracic and lumbar spine produces good results as long as the reconstructive principles are followed. A large number of suitable implants are available meanwhile to provide a short range stabilization which is essential for paraplegic patients, otherwise especially in stabilizations with rods mobility and self aid is extremely endangered. A final conclusion in respect of neurological recovery from decompression or the use of MP cannot be offered, especially as we use one or the other at the same time, but fortunately we noted an improvement in more than $50 \%$ of those with incomplete lesions. We feel strongly that the operative stabilization and MP administration is of benefit to the patient not only in respect of neurological recovery but also for possible immediate mobilization, so that the patient can play an active part in the course of readaptation at a very early time.

Regarding the time of immobilization and also the stabilization of additional fractures following the principles of the Swiss AO has been beneficial for SCI patients. A good reconstruction and functional result is essential for fractures of the upper limbs.

Although we were not able to reach our goal of giving comprehensive care and management for all freshly injured SCI patients on the day of onset, we still follow our aim as close as possible being aware, that the available SCI beds in our region are not sufficient in respect of the size of the population. The basic ideas of Guttmann are still the leading principles of our care and management despite all changes in the acute treatment of spine injuries.

\section{References}

1 Guttmann L. Spinal Cord Injuries, Comprehensive Management and Research. Blackwell: Oxford 1973.

2 Meinecke FW. Geschichte der Behandlung Querschnittgelähmter in der Bundesrepublik Deutschland. Unfallchirurgie 1988; 14: 64 73.

3 Hadra BE. Wiring of the vertebrae as a means of immobilization in fractures and Pott's disease. Medical Times and Register 1891; 22: 423. Reprint: Clin Orthop 1975; 112

4 Albee FH. Transplantation of a portion of the tibia into the spine for Pott's disease. JAMA 1911; 75: 885.

5 Holdsworth F, Hardy A. Early treatment of paraplegia from fractures of the thoraco-lumbar spine. J Bone It Surg B 1953; 35: 540.

6 Harrington PR. Instrumentation in spine instability other than scoliosis. SAfr J Surg 1967; 5: 7.

7 Roy-Camille R, Saillant G, Berteaux D, Salgado V. Osteosynthesis of thoraco-lumbar spine fractures with metal plates screwed through the vertebral pedicles. Reconstr Surg Traumatol 1976; 15: 2 .

8 Weiss M. Dynamic spine alloplasty (spring-loading corrective devices) after fracture and spinal cord injury. Clin Orthop 1975; 112: 150 .

9 Bötel U. Die Behandlung der Verrenkungsbrüche der Brust- und Lendenwirbelsäule mit der Weiss-Feder und ihre Modifikationen. Hefte z Unfallheilkunde 1980; 149: 182.

10 Magerl F. Clinical application on the thoraco-lumbar junction and the lumbar spine with a fixateur externe. In: Mears DC. External skeletal fixation. Williams and Wilkins: Baltimore 1981.

11 Dick W. 'The fixateur interne' as a versatile implant for spine surgery. Spine 1987; 12: $882-900$.

12 Dick W, Kluger P, Magerl F, Wörsdörfer O, Zäch G. A new device for internal fixation of thoraco-lumbar and lumbar spine fractures: the 'fixateur interne'. Paraplegia 1985; 23: 225-232.

13 Daniaux H, Seykora P, Genelin A, Lang T, Kathrein A. Application of posterior plating and modifications in thoracolumbar spine injuries. Indication, techniques and results. Spine 1991; 16: $125-133$

14 Riska EB, Myllynen P. Treatment of spinal fractures with paraplegia. Zbl Chirurgie 1981; 106: 355.

15 Kostuik JP. Anterior spinal cord decompression for lesions of the thoracic and lumbar spine. Techniques, new methods of internal fixation, results. Spine 1983; 8: $512-531$.

16 Robinson RA, Smith GW. Anterolateral cervical disc removal and interbody fusion for cervical disc syndrome. Bull Johns Hopk Hosp 1955; 96: $223-224$.

17 Cloward RB. Treatment of acute fractures and fracturedislocation of the cervical spine by vertebral body fusion. $J$ Neurosurg 1961; 18: 201.

18 Aebi M. Recent advances in internal fixation of cervical spine. Curr Orthop 1991; 5: 239-247.

19 Jeanneret B, Magerl F, Ward EH, Ward I Ch. Posterior stabilization of the cervical spine (C 2-7) with hook plates. Spine 1991; 16: $56-63$.

20 Meinecke FW, Exner G. Injuries of the thoraco-lumbar spine. In: Vinken PJ, Bruyn GW, Klawans HL. Handbook of Clinical Neurology. Elsevier-North Holland, Amsterdam 1993; Vol 61: $89-109$.

21 Bracken MB, Shepard MJ, Collins WF, Holford TR, Young W, Baskin DS, Eisenberg HM, Flamm E, Leo-Summers L, Maroon J, Marshall LF, Perrot PL, Piepmeier J, Sonntag VKH, Wagner FC, Wilberger JE, Winn HR. A randomized, controlled trial of methylprednisolone or naloxone in the treatment of spinal cord injury. New Engl J Med 1990; 322: $1405-1411$ 
22 Geisler FH, Dorsey FC, Colemann WP. Recovery of motor function after spinal cord injury - a randomized, placebocontrolled trial with GM-1 ganglioside. New Engl J Med 1991; 324: $1829-1838$.

23 Schwab ME. Regeneration of lesioned CNS axons by neutralisation of neurite growth inhibitors: A short review. Paraplegia 1991; 29: $294-298$.

24 Gerner HJ. Die Querschnittlähmung: Erstversorgung, BehanDlungsstrategie, rehabilitation. Blackwell: Berlin 1992.

25 Meinecke FW. Querschnittlähmungen: Bestandaufnahme und Zukunftsaussichten.. Springer: Berlin 1990.

26 Zäch GA. Rehabilitation beginnt am Unfallort - multidisziplinäre Betreuung Querschnittgelähmter in der Akutphase. Springer: Berlin 1992.

27 Möllmann HW, Barth J, Bötel U, Hochhaus G, Derendorf H, Wagner T. Ultrahigh doses of methylprednisolone in acute spinal cord injury. 20th Annual Meeting of the American College of Clinical Pharmacology, Atlanta 1991.

28 Magerl F, Aebi M, Gertzbein SD, Harms J, Nazarian S. A comprehensive classification of thoracic and lumbar injuries. Eur Spine 1994; 3: $184-201$.

29 Müller ME, Allgöwer M, Schneider R, Willenegger H. Manual of internal fixation. Springer: Berlin, Heidelberg, New York, Tokyo 1991.

30 Bötel U, Gläser E. Surgical treatment of posttraumatic deformities. In: Wittenberg RH, Steffen R. Instrumented Spinal Fusion. Thieme: Stuttgart, New York 1994. 